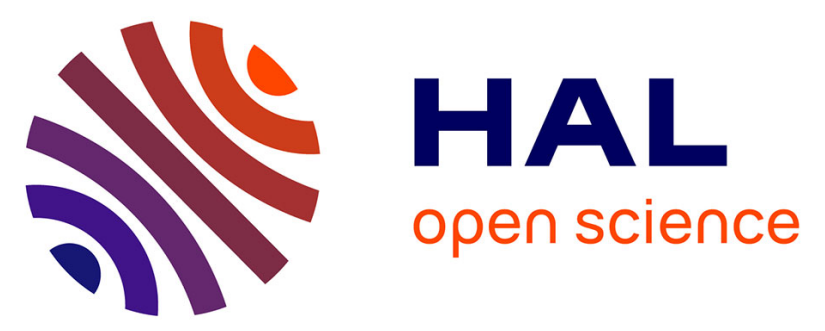

\title{
Safety, feasibility, and outcome results of cardiac resynchronization with triple-site ventricular stimulation compared to conventional cardiac resynchronization.
}

Frederic Anselme, Pierre Bordachar, Jean Luc Pasquié, Didier Klug, Christophe Leclercq, Antoine Milhem, Christine Alonso, Jean Claude Deharo, Daniel Gras, Vincent Probst, et al.

\section{To cite this version:}

Frederic Anselme, Pierre Bordachar, Jean Luc Pasquié, Didier Klug, Christophe Leclercq, et al.. Safety, feasibility, and outcome results of cardiac resynchronization with triple-site ventricular stimulation compared to conventional cardiac resynchronization.. Heart Rhythm, 2016, 13 (1), pp.183-189. 10.1016/j.hrthm.2015.08.036 . hal-01217004

HAL Id: hal-01217004

https://hal-univ-rennes1.archives-ouvertes.fr/hal-01217004

Submitted on 18 Oct 2015

HAL is a multi-disciplinary open access archive for the deposit and dissemination of scientific research documents, whether they are published or not. The documents may come from teaching and research institutions in France or abroad, or from public or private research centers.
L'archive ouverte pluridisciplinaire HAL, est destinée au dépôt et à la diffusion de documents scientifiques de niveau recherche, publiés ou non, émanant des établissements d'enseignement et de recherche français ou étrangers, des laboratoires publics ou privés. 


\section{Safety, Feasibility and outcome results of Cardiac}

\section{Resynchronization with Triple Site Ventricular Stimulation}

\section{as compared to Conventional Cardiac Resynchronization}

Frederic Anselme ${ }^{a}, M D, P h D$, Pierre Bordachar ${ }^{b}, M D, P h D$, Jean Luc Pasquiéc, MD, PhD, Didier Klug ${ }^{d}, \mathrm{MD}, \mathrm{PhD}$, Christophe Leclercq ${ }^{e}, \mathrm{MD}, \mathrm{PhD}$, Antoine Milhem ${ }^{\dagger}, \mathrm{MD}$, Christine Alonso $^{g}, \mathrm{MD}$, Jean Claude Deharo ${ }^{h}, \mathrm{MD}, \mathrm{PhD}$, Daniel Gras', MD, Vincent Probst', MD, PhD, Olivier Piot ${ }^{k}$, MD, Arnaud Savouréa ${ }^{2}$ MD

\footnotetext{
${ }^{a}$ Charles Nicolle University Hospital, 1, rue de Germont - 76000 Rouen, France ; ${ }^{b}$ Haut Lévèque University Hospital, 1, Avenue de Magellan - 33604 Pessac, France ; ' Arnaud de Villeneuve University Hospital, 371 Avenue Doyen Gaston Giraud - 34090 Montpellier, France ; ${ }^{d}$ Cardiology Hospital, Lille, Boulevard du Pr. Jules Leclercq - 59037 Lille, France ; ${ }^{\text {P}}$ Pontchaillou University Hospital, 2, rue Henri le Guilloux - 35000 Rennes, France ;'Saint Louis Hospital, rue du Dr. Schweitzer - 17000 La Rochelle, France ; ${ }^{9}$ Ambroise Paré clinic, 25 boulevard Victor Hugo - 92200 Neuilly sur Seine, France ; 'La Timone University Hospital, 264 rue Saint Pierre - 13005 Marseille, France ; 'Nouvelles cliniques Nantaises - Le Confluent, 4, rue Eric Tabarly - 44400 Nantes, France ; 'Laënnec University Hospital, Boulevard Jacques Monod - 44800 Saint Herblain, France ; ${ }^{k}$ Centre Cardiologique du Nord, 36 Rue des Moulins Gémeaux - 93200 Saint-Denis, France
}

Dr. Anselme received consultant fees from Medtronic, Sorin Group and Boston Scientific. Corresponding author : Frédéric Anselme, Centre Hospitalier Universitaire Charles Nicolle, 1 rue de Germont 76000 Rouen, France. Email : frederic.anselme@chu-rouen.fr. Tel : +33232888 111.

Frederic.anselme@chu-rouen.fr

Arnaud.savoure@chu-rouen.fr bordacharp@hotmail.com jl-pasquie@chu-montpellier.fr didier.klug@chru-lille.fr christophe.leclercq@chu-rennes.fr antoine.milhem@ch-larochelle.fr christine.alonso@wanadoo.fr JeanClaude.DEHARO@ap-hm.fr dangras@aol.com vincent.probst@chu-nantes.fr o.piot@ccncardio.com 
Background: The non-responders rate to cardiac resynchronization therapy (CRT) may be due to incomplete resynchronization as dyssynchrony can persist in about $30 \%$ of patients. We hypothesized that CRT with triple site ventricular stimulation (TRIV) may improve resynchronization and its outcomes.

Objective: We assessed the feasibility and safety of TRIV and collected data on clinical outcomes to dimension future studies.

Methods: Our pilot randomized trial was designed to assess the safety and feasibility of TRIV with 2 right and 1 left ventricular leads as compared with conventional CRT. The primary endpoint was the rate of severe adverse events (SAE) at 6 months. Secondary endpoints included functional improvement parameters, quality of life (QOL) score, and changes of echocardiographic indices at 6 and at 12 months in a subset of patients.

Results: 76 patients were enrolled at 11 centers and randomized to control or TRIV arm. All implant procedures were successful but one. At 6 month, there was no statistical difference between proportions of patients with at least one SAE in both groups $(34.1 \%$ vs. $25.7 \%, p=0.425)$. There was also no difference between functional improvement parameters, 6-minutes walking distances $(p=0.40)$, QOL scores $(p=0.27)$ and echographic indices. At 12 months, proportion of patients with a LVEF gain of more than $5 \%, 10 \%, 15 \%$ was significantly superior with TRIV.

Conclusion: TriV pacing is an effective and safe technique and may provide a greater benefit on ventricular remodeling than conventional CRT. Further studies are needed to assess its long term benefit (NCT00887237).

Keywords: cardiac resynchronization therapy; multisite pacing; congestive heart failure

\section{Introduction}

Cardiac resynchronization therapy (CRT) is a recommended treatment for selected patients with symptomatic heart failure (HF). Although most treated patients show a benefit from CRT, a lack of response is observed for about $25-30 \%$ of them ${ }^{1}$ whatever the response criteria used either based on the clinical status (NYHA class, clinical composite score) or on ventricular remodeling parameters assessed by echography (Left ventricle end of systole volume). This rate has remained remarkably stable since the therapy started and has motivated many studies to better understand the underlying physiopathology and the CRT action mechanisms.

Among the various research axes, increasing the number of pacing sites in an attempt to better homogenize the cardiac mechanical activity has been evaluated. A configuration with two RV leads and one LV lead was tested acutely in three studies $^{2,3,4}$. In all cases, it demonstrated a significant improvement of cardiac performance whether assessed by echographic parameters or LV dP/dt measurements. First results with triple-site ventricular stimulation are encouraging 
and this approach might become a treatment option for CRT candidates provided its feasibility, safety and efficacy is demonstrated at larger scale. In the present study, we focused on the safety of this pacing configuration and collected data on clinical outcomes to dimension future studies.

\section{Methods}

This was a pilot, multicenter, prospective, parallel, randomized, controlled trial conducted in 11 French centers. All patients were informed and granted their written informed consent as approved by ethics committee. Patients were enrolled in the study if they were candidate to a de novo CRT-P or CRT-D. Criteria for inclusion into the study included LV dysfunction due to either ischemic or non-ischemic cardiomyopathy with an LV ejection fraction (LVEF) $<35 \%$, New York Heart Association (NYHA) class II, III or IV functional status, and optimal medical therapy. Patients had to be in sinus rhythm with QRS duration > 120 milliseconds for NYHA class III and IV patients and > 150 milliseconds for NYHA class II patients ${ }^{5,6}$. Patients with complete AV block were excluded. Enrolled patients were randomly assigned in a 1:1 fashion to receive either a standard CRT system with a bipolar LV lead and a RV lead positioned at the RV apex (Control group) or a TRIV system (test group) with two RV leads: one positioned at the apex, the other in a high septal position, at the level of the His bundle or above. Randomization occurred in blocks within centers. The septal RV and the bipolar LV leads were connected to the LV port using parallel Y-adaptor (Medtronic model 2872). This configuration was chosen to avoid any oversensing on the RV channel. Patients were blinded for the allocated intervention. At predischarge, patients underwent $\mathrm{A}-\mathrm{V}$ delay optimization under echocardiographic guidance to maximize diastolic filling. VV delay was set to zero millisecond for all patients in both groups. Device programming was left to investigators discretion with the exception of the LV capture management feature that was left off.

\section{Data collection}

Patients underwent the following evaluations at baseline: NYHA functional class; 6-minute walking test; QOL evaluation using the Minnesota Living with Heart Failure Questionnaire (MLWHF); Echocardiography exam, which included measurement of LVEF, LV diastolic and systolic dimensions, end diastolic and systolic volumes (during all the study, echography exams were performed in a blinded fashion); and QRS width on 12-lead ECG. Duration of the procedure and acute electrical parameters values - pacing threshold and impedance, sensed signal amplitude - were collected. At each follow-up (FU) visit, pre-discharge and 6 months, the CRT system proper functioning was assessed. Threshold test in the TRIV group were performed using 12-lead ECG to better identify QRS morphology changes. Baseline variables were reevaluated three, and six months after randomization. Clinical composite score $(\mathrm{CCS})^{7}$ was evaluated at 6 month FU. The echocardiography exam and electrical parameters measurements were repeated at 12 month for all patients included in Rouen. All adverse events (AE) were reported and adjudicated by an independent AE committee that reviewed events type, severity and system-relatedness. AE were defined according to ISO14155-2003. 


\section{Study endpoints}

The primary objective of the study was to evaluate the safety of the TRIV configuration compared to standard CRT. Primary end point was the rate of severe adverse events (SAE). Secondary end points included type, rate, severity and timing of adverse events (AE), survival and proportion of patients with continuous CRT delivery, clinical composite score, NYHA class distribution in both groups, 6 minute walking distance, QOL scores, changes of echocardiographic indices of LV remodeling at 6 months. For the subset of patients followed-up at 12 months, they were considered as responders to CRT if they were alive, gained one NYHA class and had an absolute LVEF increase of more than $5 \%, 10 \%, 15 \%$.

\section{Statistics}

Data were analyzed on an intention-to-treat basis. All p values reported are nominal, and all statistical tests are 2-sided. $P$ value $<0.05$ was considered statistically significant. Data were expressed as mean $\pm S D$, if continuous, and as absolute and relative frequency, if categorical. Comparisons between continuous distributions were performed by means of 2-sample Student $t$ test or Wilcoxon test when distributions were not normal. Categorical distributions were compared by using the $\mathrm{X}^{2}$ test or the Fisher exact test for small samples. Multinomial logistic regression was used to estimate whether CCS and NYHA distributions were influenced by the tested treatment. Survival, time to first AE, time to first SAE and time to first device-related AE curves were determined by the Kaplan-Meier method. Time 0 was the date of enrolment and patients not experiencing an event were censored at 6 months FU visit date. Comparison of the 2 study groups was done using the log-rank test.

\section{Results}

First patient was enrolled in June 2009, and last patient FU was completed in January 2013; 76 patients were randomized (TRIV $=35$, control $=41)$. There were no significant baseline differences between groups (Table I). The mean LVEF was $28.7 \pm 6.3 \%$ and the mean LV end-diastolic volume was $208 \pm 74 \mathrm{ml}$. The mean intrinsic QRS and PR interval duration were $162 \pm 21$ and $194 \pm 42$ ms respectively ( $31 \%$ of patients with a PR interval > $200 \mathrm{~ms})$. CRT-Ds were implanted in two third of the patients population (65.8\%). Implant was attempted for all but one patient assigned to standard CRT group who died before implant. A prophylactic antibiotic therapy was administered prior implant to $87.8 \%$ and $94.3 \%$ of the patients in the control and Triv Group. All of the patients were implanted successfully but one for which a second attempt with LV epicardial lead placement was required. Mean procedure duration was slightly longer in the TRIV group (118 \pm 50 versus $98 \pm 37$ minutes in the control group, $p=0,066$ ). Mean $X$-ray exposure durations were similar: $17.0 \pm 12.7$ versus $18.4 \pm 11.9$ minutes $(p=0,504)$. Lead electrical parameters measured individually were also comparable with the exception of the LV pacing threshold that was slightly lower in the TRIV group $(1.48 \pm 0.85 \mathrm{~V}$ vs $1.12 \pm 0.75 \mathrm{~V}$ at $0.5 \mathrm{~ms}$ ). Loss of biventricular capture on the LV and septal RV leads connected with the Y-adaptor occurred at $1.47 \pm 0.56 \mathrm{~V}$ at $0.5 \mathrm{~ms}(0.5-2.75 \mathrm{~V})$. This latter value remained stable at pre-discharge: $1.47 \pm 0.88 \mathrm{~V}$. QRS durations decreased in both groups versus baseline : $144 \pm 26.5$ versus $136 \pm 19.4$ in control and TRIV group respectively $(p=0.16)$. Of the 41 patients assigned to the control group, 3 did not complete six months $F U-2$ died, and 1 was explanted and not re-implanted. Of the 35 patients assigned to the TRIV group, 2 deceased and did not complete 
six months of FU. No patient was lost to FU for the analysis of SAE. All patients continued to receive the assigned treatment for the intended duration of the study. Pacing thresholds remained acceptable throughout the entire study duration for most of the patients. TRIV pacing could be achieved for all of the patients with this pacing configuration however threshold was superior to $4.5 \mathrm{~V} / 0.4 \mathrm{~ms}$ for four of them.

\section{Primary end point}

At 6 month FU, there was no statistically significant difference between proportions of patients with at least one SAE in the control and TRIV groups (respectively $34.1 \%$ vs. $25.7 \%, p=0.425$ ). Time to first SAE is presented in Figure 1 . The probability of first SAE occurrence was similar in both groups (log rank test, $\mathrm{p}=0.52$ ). In particular, device related infection rates were similar, with one infection in each group.

\section{Secondary end points:}

As for SAE, proportions of patients with at least one AE were similar in both groups $(56.1 \%$ in control versus $42.9 \%$ in TRIV group, $p=0.25)$. This was also true for mortality (4.9\% versus $5.7 \%)$. None of the reported deaths were procedurerelated; all were due to terminal heart failure. Time to first $A E$, to first system-related $A E$ and to death were similar for both groups (log rank test, $p=0.46, p=0.79, p=0.88$ respectively).

A majority of patients (81.6\%) were free of any interruption of CRT delivery or occurrence of side effects. Proportion of patients with at least one system-related AE was equivalent in Control and TRIV group (19.5\% and $17.1 \%$ respectively, $\mathrm{p}=0.79)$.

Six-month CCS distributions were similar between control and TRIV group $(p=0.90)$ with a quite large proportion of responders to the therapy. Same observation was done for NYHA class distributions $(p=0.86)$ as well as for 6 -minutes walking distance $(p=0.40)$ and QOL score $(p=0.2 ;$ Table II).

At 6 month FU, there was no significant difference between the indices of LV remodeling observed in both groups: LVEF and LV dimensions improved in similar proportion (Table III).

In the subset of patient followed-up at 12 months, there was no difference regarding proportion of patients with SAE (60\% for controls versus $50 \%$ for TRIV patients). Compared to baseline, the improvement of the 6 minutes walking distance was not significant and was similar in both groups. QOL score improved significantly only in the TRIV group $(p=0.03)$. LVEF and changes of LVEF was significantly superior in the TRIV group compared to the control group. Also the proportion of responders' patients with LVEF gain of more than $5 \%, 10 \%$, and $15 \%$ was significantly superior in the TRIV group (Table IV). Finally there was a trend towards a greater proportion of patients with LVESV decrease of more than $15 \%$ and $25 \%$ in the TRIV group as compared to controls ( $85 \%$ versus $66 \%$; $69 \%$ versus $47 \%$ respectively).

\section{Discussion}


This is the first chronic prospective randomized study comparing conventional biventricular and TRIV pacing with the use of two RV leads.

\section{Feasibility:}

We demonstrated that implanting an additional RV lead for CRT is feasible and safe, and does not interfere with the proper device functioning including tachyarrhythmia management. Conversely to other multi -site pacing approaches using two LV leads, where procedure feasibility may be limited by the ability to successfully implant the second LV lead in a stable and appropriate position, our implant success rate was of $100 \%$. Noteworthy, this was achieved without significantly prolonging procedure duration, highlighting the easiness of the implant technique. This was expected as the main driver for procedure duration is most of the time related to LV lead implantation. In published series on dual LV pacing, the implant success rate ranged from 85 to $100 \% \%^{8,9,10}$. In study by Lenarczyk et al., implantation of a second LV lead resulted in a 30 min prolongation of procedure duration associated with a significant increase in $\mathrm{X}$-ray exposure ${ }^{10}$.

In addition, TRIV was appropriately delivered throughout the entire FU duration. Although the $\mathrm{Y}$ connector enlarged the pocket size and limited the choice of LV lead pacing vectors, we did not observe a significant increase in device related AE. Of importance, as already mentioned by Lenarczyk, device related infection rate was low: only one was reported in each group. However, we cannot strongly conclude on this point as the design of our study did not allow capturing longterm potential system-related infections. There is compelling evidence from long-term FU in large populations showing that infection risk increases with the number of leads and the number of re-operations.

High ventricular thresholds were observed in only four patients in the TRIV group. This is likely related to the dissipation of part of the delivered pacing energy through the $Y$ connector. A dedicated 4-channels device would definitely overcome these problems. In any case, the use of an additional pacing site will necessarily result in an increase of energy consumption which consequently will alter battery longevity.

Increasing the number of implanted leads could promote vein thrombosis. Even though this was not systematically assessed, no clinical symptoms related to such an event were reported.

\section{Clinical impact:}

At 6 month FU, QoL, 6 min walking test and CCS evaluation significantly improved in both study groups. Conversely to what has been observed in TRIP HF study, we did not observe any additional clinical benefit provided by the TRIV pacing configuration at the time of FU. However, we did observe a significant improvement of LVEF and a trend towards a greater proportion of patients with LVESV decrease in the subset of patients followed up at 12 months. Proportion of responders was significantly higher in the TRIV group whatever the defined threshold value for LVEF changes $(5 \%$, $10 \%, 15 \%$ ). This reflects the fact that not only the long term response rate to CRT is higher but also the amplitude of response (super-responder rate) is much greater in the TRIV group as compared to the conventional group. It appears 
that the additional benefit of TRIV configuration requires time to be detected as if the effect of TRIV lasted much longer than BIV on ventricular remodeling. This would explain by itself both the greater response rate and the greater LVEF improvement associated with TRIV.

Some authors tested dual RV pacing alone. It appears to produce a beneficial clinical response in CRT candidates on an acute and long-term basis ${ }^{11}$. However, the remodeling effect of bifocal RV pacing is generally inferior to that of conventional biventricular pacing ${ }^{12}$. Several studies have been performed on the positioning of RV and LV pacing leads and their influence on the quality of resynchronization. Some authors compared septal versus apical positioning of the $\mathrm{RV}$ lead without demonstrating any difference in terms of clinical outcomes ${ }^{13}$. Others proposed to optimize RV lead positioning based on the echographic measurement of the aortic pre-ejection delay ${ }^{2}$ while others positioned the LV lead at the site of the latest mechanical activation ${ }^{14,15,16,17}$. Benefit of these approaches could be demonstrated through single centers studies. However, their implementation can be limited by constraints of the cardiac venous anatomy and may not be easy to reproduce at larger scale on a practical standpoint. Advanced echo measurements to detect sites of latest mechanical activation may be technically challenging ${ }^{14}$. ${ }^{17}$. In addition their reproducibility remains arguable ${ }^{18}$. LV endocardial pacing looks promising ${ }^{19}$ even though it requires lifelong anti-coagulation treatment. A larger scale evaluation is now required to ensure procedure and long-term safety and evaluate more precisely clinical outcomes.

It has been also proposed to reduce the number of pacing leads seeking for LV fusion. This pacing configuration, mainly dedicated to patients with $\mathrm{LBBB}$, normal $\mathrm{AV}$ and RV conduction, could be an attractive option but its interest is not yet strongly demonstrated ${ }^{20}$.

Last, several authors proposed to increase the number of pacing sites in order to improve CRT effectiveness. One of the reasons for the lack of response to conventional CRT may be the presence of functional or fixed lines of conduction block within the left ventricle and slow ventricular activation. This latter could be due to slow electrical interventricular conduction or abnormal electro-mechanical coupling. Multiplying the pacing points could potentially overcome all of these patho-physiological abnormalities and significantly shorten the global LV activation time. With the advent of quadripolar LV leads, initially proposed as a mean to avoid phrenic nerve stimulation, some preliminary data suggest that they could also provide hemodynamic benefit ${ }^{21}$. The latter could be related to the ability to pace from the basal or mid-LV region without compromising lead stability. Although the four poles are close together, it may also be related to the ability to simultaneously pace from all electrodes ${ }^{22}$. The impact on CRT efficiency remains to be proven chronically on large scale (MORE CRT MPP study; NCT02006069). A better mechanical resynchronization may be obtained using a third ventricular lead remotely positioned from the others. Several pacing configurations have been tested including either an additional LV or RV lead. A configuration with two LV leads was evaluated in two studies performed on de novo patients ${ }^{8,9}$ with promising results on the echographic and clinical parameters. We believe that the $2 R V+1 L V$ approach is not so different than the $1 R V+2 L V$ approach in terms of resynchronization effect. Provided that the pacing leads are positioned far enough one from each other, the paced areas would be close: a high septal RV lead would be near to a LV lead positioned in the great cardiac vein, while an apical RV lead would be near to a LV lead positioned in a 
posterior/postero-lateral vein. According to electrical and anatomical characteristics, one approach rather than the other might suit better to a given patient.

\section{Study limitations}

The size of the population precludes drawing any definite conclusion on the clinical relevance of this technique. This was a pilot study designed to validate feasibility and build hypothesis for future studies. The pre-specified efficacy endpoints demonstrated no significant difference at 6 months while we observed a significant impact of TRIV pacing on a smaller sample at 12 months. Although it is possible that this technique may only convey modest incremental benefits, we still believe it is worth to perform a larger and longer term study to demonstrate its superiority. Echocardiographic evaluation was not performed in a core lab. All of the exams were done in a blinded fashion even though the sonographer may have visualized the leads. Most of the patients were enrolled in Rouen. However a potential center effect in the study results was ruled out. Also, only patients enrolled in Rouen were followed-up at one year. This implied lack of patient selection bias and only limited variations in echo measurements method in this subset of patients.

\section{Conclusion}

Our study supports TriV pacing as an effective and safe tool to improve patient clinical status. Larger studies are needed to assess the long term clinical benefit of this new pacing modality.

\section{Acknowledgements}

This study was sponsored by Medtronic.

\section{References}

\footnotetext{
${ }^{1}$ Chung ES, Leon AR, Tavazzi L et al. Results of the Predictors of Response to CRT (PROSPECT) Trial. Circulation. 2008 May 20;117(20):2608-16.

${ }^{2}$ Moubarak G, Ritter P, Daubert JC, Cazeau S. First experience of intraoperative echocardiography-guided optimization of cardiac resynchronization therapy delivery. Arch Cardiovasc Dis. 2014 Mar;107(3):169-77

${ }^{3}$ Yoshida K, Seo Y, Yamasaki H, Tanoue K, Murakoshi N, Ishizu T, Sekiguchi Y, Kawano S, Otsuka S, Watanabe S, Yamaguchi I, Aonuma K. Effect of triangle ventricular pacing on haemodynamics and dyssynchrony in patients with advanced heart failure: a comparison study with conventional bi-ventricular pacing therapy. Eur Heart J.
}

2007; 28:2610-9 
${ }^{4}$ Anselme F, Savoure A., Godin B., Auquier N., Bouchinet F. Increase of responder rate at one year with triple site ventricular stimulation as compared to conventional cardiac resynchronization. Heart Rhythm, Vol. 11, No. 5, May Supplement 2014. Abstract AB17-01.

${ }^{5}$ Vardas PE, Auricchio A, Blanc JJ, Daubert JC, Drexler H, Ector H, Gasparini M, Linde C, Morgado FB, Oto A, Sutton R, Trusz-Gluza M. Guidelines for cardiac pacing and cardiac resynchronization therapy: the task force for cardiac pacing and cardiac resynchronization therapy of the European Society of Cardiology. Developed in collaboration with the European Heart Rhythm Association Eur Heart J. 2007; 28:2256-95

${ }^{6}$ Dickstein K, Vardas PE, Auricchio A, Daubert JC, Linde C, McMurray J, Ponikowski P, Priori SG, Sutton R, van Veldhuisen DJ. 2010 Focused Update of ESC Guidelines on device therapy in heart failure: an update of the 2008 ESC Guidelines for the diagnosis and treatment of acute and chronic heart failure and the 2007 ESC guidelines for cardiac and resynchronization therapy. Eur Heart J 2010;31(21):2677-2687

${ }^{7}$ Packer, M. Proposal for a new clinical end point to evaluate the efficacy of drugs and devices in the treatment of chronic heart failure. Journal of Cardiac Failure. 2001; 7: 176-182.

${ }^{8}$ Leclercq C, Gadler F, Kranig W, Ellery S, Gras D, Lazarus A, Clémenty J, Boulogne E, Daubert JC. A Randomized Comparison of Triple-Site Versus Dual-Site Ventricular Stimulation in Patients With Congestive Heart Failure. J Am Coll Cardiol 2008;51:1455-62)

${ }^{9}$ Lenarczyk R, Kowalski O, Kukulski T, Szulik M, Pruszkowska-Skrzep P, Zielinska T, Kowalczyk J, Pluta S, Duszanska A, Sredniawa B, Musialik-Łydka A, Kalarus Z. Triple-site biventricular pacing in patients undergoing cardiac resynchronization therapy: a feasibility study. Europace. 2007 Sep;9(9):762-7.

${ }^{10}$ Lenarczyk R, Kowalski O, Sredniawa B, Pruszkowska-Skrzep P, Mazurek M, Jedrzejczyyk-Patej E, Wozniak A, Pluta S, Glowacki J, Kalarus Z. Implantation Feasibility, Procedure-Related Adverse Events and Lead Performance During 1-Year Follow-Up in Patients Undergoing Triple-Site Cardiac Resynchronization Therapy: A Substudy of TRUST CRT Randomized Trial. J Cardiovasc Electrophysiol, Vol. 23, pp. 1228-1236, November 2012. 
${ }^{11}$ Res JC, Bokern MJ, de Cock CC, van Loenhout T, Bronzwaer PN, Spierenburg HA; BRIGHT Investigators. The BRIGHT study: bifocal right ventricular resynchronization therapy: a randomized study. Europace. 2007 Oct;9(10):857-61.

${ }^{12}$ Barold SS, Audoglio R, Ravazzi PA, Diotallevi P. Is bifocal right ventricular pacing a viable form of cardiac resynchronization? Pacing Clin Electrophysiol. 2008 Jul;31(7):789-94.

${ }^{13}$ Kristiansen HM, Vollan G, Hovstad T, Keilegavlen H, Faerestrand S. A randomized study of haemodynamic effects and left ventricular dyssynchrony in right ventricular apical vs. high posterior septal pacing in cardiac resynchronization therapy. Eur J Heart Fail. 2012 May;14(5):506-16.

${ }^{14}$ Saba S, Marek J, Schwartzman D, Jain S, Adelstein E, White P, Oyenuga OA, Onishi T, Soman P, Gorcsan J 3rd. Echocardiography guided left ventricular lead placement for cardiac resynchronization therapy: results of the Speckle Tracking Assisted Resynchronization Therapy for Electrode Region trial. Circ Heart Fail 2013; 6:427-34.

${ }^{15}$ Khan FZ, Virdee MS, Palmer CR, Pugh PJ, O'Halloran D, Elsik M, Read PA, Begley D, Fynn SP, Dutka DP. Targeted left ventricular lead placement to guide cardiac resynchronization therapy: the TARGET study: a randomized, controlled trial. J Am Coll Cardiol 2012;59: 1509-18.

${ }^{16}$ Zanon F, Baracca E, Pastore G, Fraccaro C, Roncon L, Aggio S, Noventa F, Mazza A, Prinzen F. Determination of the longest intrapatient left ventricular electrical delay may predict acute hemodynamic improvement in patients after cardiac resynchronization therapy. Circ Arrhythm Electrophysiol. 2014 Jun;7(3):37783.

17 Adelstein E, Alam MB, Schwartzman D, Jain S, Marek J, Gorcsan J, Saba S. Effect of echocardiographyguided left ventricular lead placement for cardiac resynchronization therapy on mortality and risk of defibrillator therapy for ventricular arrhythmias in heart failure patients (from the Speckle Tracking Assisted Resynchronization Therapy for Electrode Region [STARTER] trial), Am J Cardiol, 2014;113:1518-22.

${ }^{18}$ Chung ES, Leon AR, Tavazzi L, et al. Results of the Predictors of Response to CRT (PROSPECT) trial. Circulation. 2008 May 20;117(20):2608-16.

${ }^{19}$ Auricchio A, Delnoy PP, Butter C, Brachmann J, Van Erven L, Spitzer S, Moccetti T, Seifert M, Markou T, Laszo K, Regoli F; Collaborative Study Group. Feasibility, safety, and short-term outcome of leadless ultrasound- 
based endocardial left ventricular resynchronization in heart failure patients: results of the Wireless Stimulation Endocardially for CRT (WiSE-CRT) study. Europace. 2014 May;16(5):681-8

${ }^{20}$ Martin DO, Lemke B, Birnie D et al. Investigation of a novel algorithm for synchronized left-ventricular pacing and ambulatory optimization of cardiac resynchronization therapy: results of the adaptive CRT trial. Heart Rhythm. 2012 Nov;9(11):1807-14.

${ }^{21}$ Osca J, Alonso P, Cano O, Sánchez JM, Tejada D, Andrés A, Sancho Tello MJ, Olagüe J. The Use of Quadripolar Left Ventricular Leads Improves the Hemodynamic Response to Cardiac Resynchronization Therapy. Pacing Clin Electrophysiol. 2015 Mar;38(3):326-33.

${ }^{22}$ Zanon F, Baracca E, Pastore G et al. Multipoint Pacing by a Left Ventricular Quadripolar Lead Improves the Acute Hemodynamic Response to CRT Compared with Conventional Biventricular Pacing at any Site. Heart Rhythm. 2015 May;12(5):975-81.

\section{Legend figure 1}

BiV (conventional CRT)

TriV

X-axis: Month

Y-axis: Proportion of patients free from severe adverse event

\section{Title figure 1}

Kaplan-Meier estimates of the time to first severe adverse event

\section{Clinical perspectives}

This is the first chronic prospective randomized study comparing conventional biventricular and triple site ventricular pacing with the use of two RV leads (TRIV). Our study supports TRIV as an effective and safe tool to improve patient clinical status. Development of new device technology is required to limit the drawbacks induced by the addition of a third lead and its impact on battery longevity (multi-port can). Although at mid-term follow-up, there was no significant difference between groups regarding clinical status, we observed an encouraging trend towards a better LV remodeling at 1-year in the TRIV group. The additional benefit of TRIV configuration may require time to be detected as if the effect 
of TRIV pacing lasted much longer than BIV on ventricular remodeling. This would explain both the greater response rate and the greater LVEF improvement associated with TRIV we found in our study. A larger and longer term study is needed to demonstrate the potential superiority of this pacing technique over conventional CRT in order to be translated into daily clinical practice.

\begin{tabular}{|c|c|c|c|c|}
\hline & All & Control & TRIV & $p$ \\
\hline $\mathbf{n}$ & 76 & 41 & 35 & \\
\hline Age (year) & $69.4 \pm 10.7$ & $69.9 \pm 10.5$ & $68.9 \pm 11.2$ & 0.71 \\
\hline$\%$ male & $71.1 \%$ & $61 \%$ & $82.9 \%$ & 0.04 \\
\hline Ischemic heart disease (\%) & $43.4 \%$ & $43.9 \%$ & $42.9 \%$ & 0.93 \\
\hline Paroxysmal AF (\%) & $26.3 \%$ & $26.8 \%$ & $25.7 \%$ & 0.91 \\
\hline QRS duration (ms) & $162 \pm 21$ & $160 \pm 21$ & $164 \pm 21$ & 0.20 \\
\hline CRT-D proportion (\%) & $65.8 \%$ & $63.4 \%$ & $68.6 \%$ & 0.64 \\
\hline $\begin{array}{l}\text { NYHA class } \\
\% \text { II } \\
\% \text { III } \\
\% \text { IV }\end{array}$ & $\begin{array}{c}6.6 \% \\
85.5 \% \\
7.9 \%\end{array}$ & $\begin{array}{c}12.2 \% \\
80.5 \% \\
7.3 \%\end{array}$ & $\begin{array}{c}0 \% \\
91.4 \% \\
8.6 \%\end{array}$ & 0.09 \\
\hline LVEF (\%) & $28.7 \pm 6.3 \%$ & $29.6 \pm 6.3 \%$ & $27.7 \pm 6.4 \%$ & 0.12 \\
\hline LV end of diastole volume (ml) & $202 \pm 70.7$ & $208 \pm 73.8$ & $195 \pm 67.5$ & 0.55 \\
\hline LV end of systole volume (mI) & $145 \pm 58.9$ & $147 \pm 61.8$ & $144 \pm 56.4$ & 0.96 \\
\hline LV end of diastole diameter $(\mathrm{mm})$ & $66.7 \pm 9.76$ & $66.9 \pm 10,5$ & $66.5 \pm 8.99$ & 0.86 \\
\hline LV end of systole diameter (mm) & $57.4 \pm 11.5$ & $58.6 \pm 11.6$ & $55.9 \pm 11.4$ & 0.31 \\
\hline 6 minute walking distance $(\mathrm{m}) / \mathrm{n}$ & $309 \pm 111 / 66$ & $304 \pm 98 / 36$ & $315 \pm 125 / 30$ & 0.68 \\
\hline QOL score & $37.2 \pm 18.1$ & $36.5 \pm 19.8$ & $38.0 \pm 16.2$ & 0.73 \\
\hline
\end{tabular}

Table I: Population characteristics at baseline

\begin{tabular}{|c|c|c|c|c|c|c|c|c|c|c|}
\hline & \multicolumn{5}{|c|}{ Baseline } & \multicolumn{5}{|c|}{6 month FU } \\
\hline & $n$ & Control & $\mathbf{n}$ & TRIV & p & $\mathbf{n}$ & Control & $\mathbf{n}$ & TRIV & p \\
\hline $\begin{array}{l}\text { Clinical composite score: } \\
\% \text { Improved } \\
\% \text { Unchanged } \\
\% \text { Worsened } \\
\end{array}$ & & & & & & 38 & $\begin{array}{c}81.6 \% \\
13.2 \% \\
5.2 \%\end{array}$ & 33 & $\begin{array}{c}78.8 \% \\
18.2 \% \\
3.0 \%\end{array}$ & $\mid 0.90$ \\
\hline $\begin{array}{l}\text { NYHA class: } \\
\% \text { I } \\
\% \text { II } \\
\% \text { III } \\
\% \text { IV } \\
\end{array}$ & 41 & $\begin{array}{c}0 \% \\
12.2 \% \\
80.5 \% \\
7.3 \% \\
\end{array}$ & 35 & $\begin{array}{c}0 \% \\
0 \% \\
91.4 \% \\
8.6 \% \\
\end{array}$ & 0.09 & 38 & $\begin{array}{c}21.1 \% \\
55.3 \% \\
23.7 \% \\
0 \% \\
\end{array}$ & 33 & $\begin{array}{c}18.2 \% \\
63.6 \% \\
18.2 \% \\
0 \% \\
\end{array}$ & $\mid 0.86$ \\
\hline 6 min. walking distance $(\mathrm{m})$ & 36 & $304 \pm 98$ & 30 & $315 \pm 125$ & 0.68 & 33 & $377 \pm 97$ & 32 & $355 \pm 117$ & 0.40 \\
\hline QOL Score & 41 & $38.0 \pm 16.2$ & 35 & $37.2 \pm 18.1$ & 0.73 & 36 & $29.6 \pm 23.2$ & 33 & $22.2 \pm 16.1$ & 0.27 \\
\hline
\end{tabular}

Table II: Functional status at baseline and 6 month FU 


\begin{tabular}{|l|c|c|c|c||c|c|c|c|c||c|}
\cline { 2 - 10 } \multicolumn{1}{c|}{} & \multicolumn{4}{c|}{ Baseline } & \multicolumn{4}{c|}{ 6 Month FU } \\
\cline { 2 - 11 } \multicolumn{1}{c|}{} & $\mathbf{n}$ & Control & $\mathbf{n}$ & TRIV & $\mathbf{p}$ & $\mathbf{n}$ & Control & $\mathbf{n}$ & TRIV & $\mathbf{p}$ \\
\hline LVEF (\%) & 41 & $29.6 \pm 6.3$ & 35 & $\begin{array}{c}27.7 \pm 6.4 \\
\%\end{array}$ & 0.12 & 36 & $39.7 \pm 11.2$ & 32 & $41.9 \pm 11.1$ & 0.43 \\
\hline LV end of diastole volume $(\mathrm{ml})$ & 39 & $208 \pm 73.8$ & 35 & $195 \pm 67.5$ & 0.55 & 31 & $159 \pm 66.2$ & 31 & $160 \pm 71.2$ & 0.95 \\
\hline LV end of systole volume $(\mathrm{ml})$ & 38 & $147 \pm 61.8$ & 35 & $144 \pm 56.4$ & 0.96 & 30 & $95.9 \pm 57.8$ & 31 & $104 \pm 60.5$ & 0.71 \\
\hline $\begin{array}{l}\text { LV end of diastole diameter } \\
\text { (mm) }\end{array}$ & 41 & $66.9 \pm 10,5$ & 35 & $66.5 \pm 8.99$ & 0.86 & 34 & $61.1 \pm 10.2$ & 32 & $60.2 \pm 9.8$ & 0.72 \\
\hline $\begin{array}{l}\text { LV end of systole diameter } \\
\text { (mm) }\end{array}$ & 41 & $58.6 \pm 11.6$ & 34 & $55.9 \pm 11.4$ & 0.31 & 32 & $50.9 \pm 12.7$ & 30 & $50.0 \pm 10.4$ & 0.76 \\
\hline
\end{tabular}

Table III: Echocardiographic parameters at baseline and 6 month FU

\begin{tabular}{|c|c|c|c|c|c|c|c|}
\hline & \multicolumn{3}{|c|}{ Control $(n=20)$} & \multicolumn{3}{|c|}{$\operatorname{TRIV}(\mathrm{n}=20)$} & \multirow[t]{2}{*}{$\mathbf{p}^{*}$} \\
\hline & Baseline & $12 \mathrm{M}-\mathrm{FU}$ & p & Baseline & $12 \mathrm{M}-\mathrm{FU}$ & $p$ & \\
\hline LVEF (\%) & $26.8 \pm 6.6$ & $35.1 \pm 11$ & $<0.01$ & $26.4 \pm 5.3$ & $44.5 \pm 11$ & $<0.001$ & 0.01 \\
\hline Responders rate with LVEF gain $>5 \%$ & \multicolumn{3}{|c|}{$40 \%$} & \multicolumn{3}{|c|}{$70 \%$} & 0.05 \\
\hline Responders rate with LVEF gain $>10 \%$ & \multicolumn{3}{|c|}{$25 \%$} & \multicolumn{3}{|c|}{$60 \%$} & 0.02 \\
\hline Responders rate with LVEF gain $>15 \%$ & \multicolumn{3}{|c|}{$15 \%$} & \multicolumn{3}{|c|}{$45 \%$} & 0.03 \\
\hline LV end of systole volume (ml) & $155 \pm 60$ & $119 \pm 68$ & $<0.01$ & $163 \pm 57$ & $100 \pm 59$ & $<0.001$ & 0.35 \\
\hline Proportion with LVESV decrease $>15 \%$ & \multirow{2}{*}{\multicolumn{3}{|c|}{$\frac{66 \%}{47 \%}$}} & \multirow{2}{*}{\multicolumn{3}{|c|}{$\begin{array}{l}85 \% \\
69 \%\end{array}$}} & 0.25 \\
\hline Proportion with LVESV decrease $>25 \%$ & & & & & & & 0.21 \\
\hline LV end of diastole volume (ml) & $210 \pm 65$ & $176 \pm 80$ & $<0.05$ & $222 \pm 71$ & $171 \pm 82$ & $<0.01$ & 0.85 \\
\hline LV end of diastole diameter (mm) & $71 \pm 11$ & $66 \pm 12$ & $<0.05$ & $71 \pm 7$ & $63 \pm 11$ & $<0.01$ & 0.41 \\
\hline LV end of systole diameter $(\mathrm{mm})$ & $61 \pm 12$ & $54 \pm 15$ & $<0.05$ & $60 \pm 7$ & $47 \pm 12$ & $<0.001$ & 0.11 \\
\hline Left pre-ejection interval (ms) & $151 \pm 30$ & $134 \pm 27$ & NS & $147 \pm 25$ & $126 \pm 23$ & 0.08 & 0.32 \\
\hline Inter-ventricular delay (ms) & $46 \pm 30$ & $22 \pm 13$ & $<0.05$ & $37 \pm 26$ & $23 \pm 13$ & 0.05 & 0.81 \\
\hline LV filling time (\% RR) & $45 \pm 10$ & $45 \pm 8$ & NS & $44 \pm 9$ & $47 \pm 13$ & NS & 0.56 \\
\hline NYHA Class I/II/III/IV (n) & $0 / 2 / 16 / 2$ & $4 / 9 / 5 / 0$ & & $0 / 0 / 19 / 1$ & $8 / 7 / 1 / 0$ & & \\
\hline 6-minutes walking distance $(\mathrm{m})$ & $300 \pm 108$ & $376 \pm 106$ & 0.27 & $363 \pm 119$ & $446 \pm 87$ & 0.15 & 0.04 \\
\hline QOL Score & $43 \pm 21$ & $32 \pm 26$ & 0.16 & $36 \pm 16$ & $24 \pm 18$ & 0.03 & 0.3 \\
\hline
\end{tabular}

*BiV vs TriV at 12-month FU

Table IV: Patient characteristics at baseline and 12 month FU in the subset of patients enrolled in Rouen 


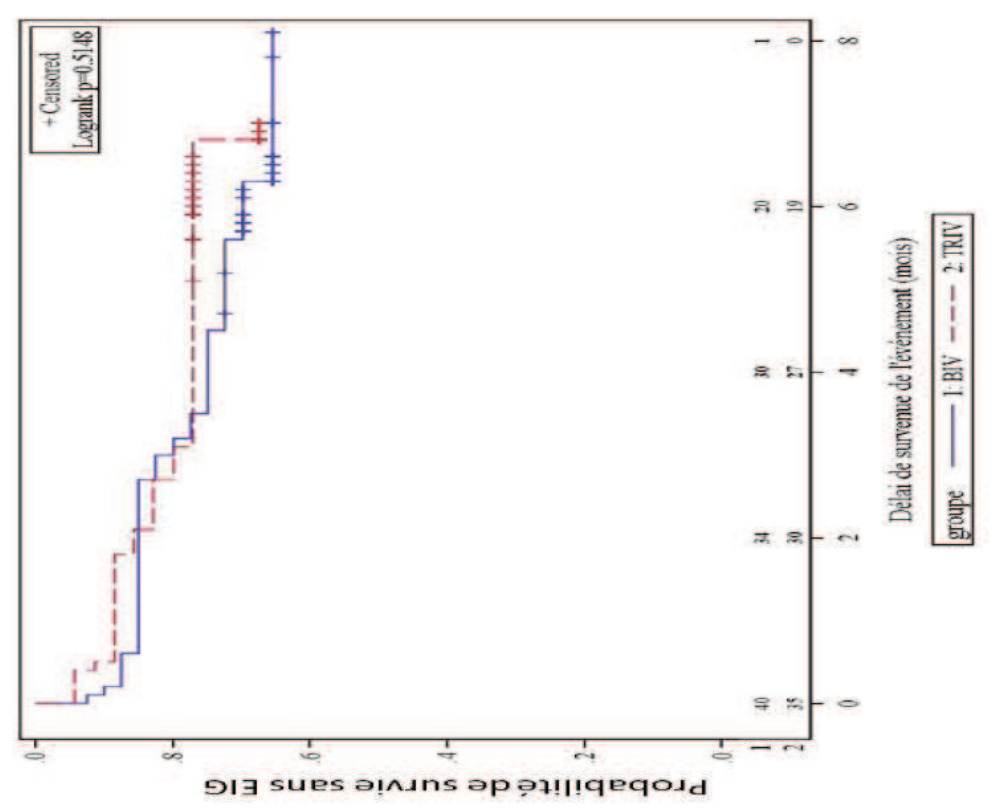

